Article

\title{
A Novel Planar Grounded Capacitively Coupled Contactless Conductivity Detector for Microchip Electrophoresis
}

\author{
Jianjiao Wang ${ }^{1}$, Yaping Liu ${ }^{1}$, Wenhe He ${ }^{2} \mathbb{D}$, Yuanfen Chen ${ }^{1} \mathbb{D}$ and Hui You ${ }^{1, * \mathbb{D}}$ \\ 1 School of Mechanical Engineering, Guangxi University, Nanning 10593, China;

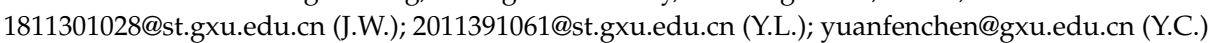 \\ 2 School of Electrical Engineering, Guangxi University, Nanning 10593, China; 1812401002@st.gxu.edu.cn \\ * Correspondence: usmlhy@iim.ac.cn
}

check for updates

Citation: Wang, J.; Liu, Y.; He, W.; Chen, Y.; You, H. A Novel Planar Grounded Capacitively Coupled Contactless Conductivity Detector for Microchip Electrophoresis.

Micromachines 2022, 13, 394. https:// doi.org/10.3390/mi13030394

Academic Editor: Antonio Ramos

Received: 30 January 2022

Accepted: 25 February 2022

Published: 28 February 2022

Publisher's Note: MDPI stays neutral with regard to jurisdictional claims in published maps and institutional affiliations.

Copyright: (C) 2022 by the authors. Licensee MDPI, Basel, Switzerland. This article is an open access article distributed under the terms and conditions of the Creative Commons Attribution (CC BY) license (https:// creativecommons.org/licenses/by/ $4.0 /)$.

\begin{abstract}
In the microchip electrophoresis with capacitively coupled contactless conductivity detection, the stray capacitance of the detector causes high background noise, which seriously affects the sensitivity and stability of the detection system. To reduce the effect, a novel design of planar grounded capacitively coupled contactless conductivity detector (PG-C4D) based on printed circuit board (PCB) is proposed. The entire circuit plane except the sensing electrodes is covered by the ground electrode, greatly reducing the stray capacitance. The efficacy of the design has been verified by the electrical field simulation and the electrophoresis detection experiments of inorganic ions. The baseline intensity of the PG-C4D was less than 1/6 of that of the traditional C4D. The PG-C4D with the new design also demonstrated a good repeatability of migration time, peak area, and peak height ( $n=5$, relative standard deviation, RSD $\leq 0.3 \%, 3 \%$, and $4 \%$, respectively), and good linear coefficients within the range of $0.05-0.75 \mathrm{mM}\left(\mathrm{R}^{2} \geq 0.986\right)$. The detection sensitivity of $\mathrm{K}^{+}, \mathrm{Na}^{+}$, and $\mathrm{Li}^{+}$reached $0.05,0.1$, and $0.1 \mathrm{mM}$ respectively. Those results prove that the new design is an effective and economical approach which can improve sensitivity and repeatability of a PCB based PG-C4D, which indicate a great application potential in agricultural and environmental monitoring.
\end{abstract}

Keywords: microchip electrophoresis; stray capacitance; capacitively coupled contactless conductivity detection; planar grounded electrode

\section{Introduction}

Microchip electrophoresis has the characteristics of small size $\left(\sim \mathrm{cm}^{2}\right)$ and short separation channels, which is efficient and convenient for on-site and real-time detection. Combined with C4D, microchip electrophoresis device is easy to miniaturize, avoiding solution contamination, as well as large and precise instrument requirement. Thus, C4D technology has been widely applied in capillary electrophoresis and microchip electrophoresis [1-4].

C4D was first proposed independently by Zemann et al. [5] and da Silva et al. [6], applied in capillary electrophoresis. Subsequently, Pumera and Wang [7] replaced the tubular electrode in C4D with two flat aluminum sheets and applied it in microchip electrophoresis. When the sample passed through the detection cell along the channel, the change of the local impedance caused the change of the alternating current on the pick-up electrode. After rectification, filtering, and amplification, the current on pick-up electrode was sampled and displayed as peaks [8,9].

At present, the common problems in microchip electrophoresis with C4D are high baseline background intensity, serious noise interference, poor detection sensitivity, and repeatability. These problems are mainly caused by stray capacitance and wall capacitance [10-12]. The wall capacitance can be reduced by integrated designs to control the thickness and material of the insulating layer [13-15]. Moreover, reasonably increasing the excitation frequency can also reduce the influence of wall capacitance. However, integrated designs are usually slightly more complex and increase the cost of the system. Meanwhile, 
increasing the operating frequency will increase the interference caused by stray capacitance. In severe cases, the interference even dominates the detector output, which has a fatal impact on the detection performance.

The method of arranging a ground electrode between the sensing electrodes to reduce the stray capacitance has been widely applied [8,16-19]. However, it is generally considered that its effect on reducing stray capacitance is limited. Based on the idea of ground electrode, Guijt et al. [20] built an integrated device design on a PCB to study the effect of insulation thickness on detection performance. Mahanadi et al. [21] added a pair of sensing electrodes to the traditional structure, forming a dual top-bottom geometry. This method doubled the coupling efficiency of the electrodes. However, the designs of microchip and electrodes are complicated, which may be the reason this method has not been adopted widely.

The other way is to counteract the adverse effects of stray capacitance and wall capacitance according to differential mode and impedance cancellation (circuit resonance) principle. Based on the principle of impedance cancellation, Shen et al. [22,23] obtained the minimum impedance with a low-impedance capacitively coupled contactless conductivity detector (LIC4D) at the resonance frequency. This method is achieved by connecting a piezoelectric quartz crystal (PQC, acts as an inductor) in series between the $\mathrm{C} 4 \mathrm{D}$ cell and the excitation signal. Compared with traditional C4Ds, the signal-to-noise ratio of LIC4D was increased by more than 20 times. One problem is that the operating frequency of the actual inductor was difficult to adjust [24]. Based on differential mode, Laugere [25] introduced an integrated four-electrode design of the detector. Compared with the traditional bipolar configuration, the reported detector had a better signal-to-noise ratio in a wide frequency range, as low as $600 \mathrm{~Hz}$. Georg Fercher [26] also adopted the similar method, and the obtained experimental result showed that the baseline intensity was greatly reduced, and the detection sensitivity was increased by several times. Xiao [27] and Stojkovic M et al. [28] introduced differential mode into capillary electrophoresis, which also improved the sensitivity of the system. Although many researchers have proposed solutions to counteract the adverse effects of stray capacitance, complex design requires complicated and strict fabrication processes and increases the cost of the system. An economical, easyto-fabricate, sensitive C4D design for microchip electrophoresis is in demand, especially for the large-scale applications in environmental monitoring.

In this study, we described a planar grounded C4D (PG-C4D) based on PCB for microchip electrophoresis. The electrophoretic responses demonstrated that the PG-C4D had smaller background baseline intensity than traditional C4D, which can be attributed to the reduction in stray capacitance. Subsequently, the electrophoretic detection of three inorganic cations, $\mathrm{K}^{+}, \mathrm{Na}^{+}$, and $\mathrm{Li}^{+}$, proved that PG-C4D had better signal-to-noise ratio and repeatability. This simple manufactured, low-cost, and sensitive PG-C4D for microchip electrophoresis has great potential application in field applications.

\section{Materials and Methods}

\subsection{Prototyping of Microfluidic Devices}

The layout of the microchip device with PCB based PG-C4D is shown in Figure 1. The microchip was secured on the PCB based C4D using a clamp and two screws, as shown in Figure 1A. The C4D electrodes were fabricated on a commercially available PCB (Shenzhen JLC Electronics Co., Ltd., Shenzhen, China). The solder mask was removed to reduce the distance between the electrodes and the microchip. The C4D electrodes were composed of a pair of sensing electrodes ( $1 \mathrm{~mm}$ width, $2 \mathrm{~mm}$ length, and $35 \mu \mathrm{m}$ thickness) and a ground electrode. The sensing electrodes were spaced by an $800 \mu \mathrm{m}$ gap, optimized in the previous reported work from our group [29]. The difference between the PG-C4D and the traditional $\mathrm{C} 4 \mathrm{D}$ was the ground electrode design. The ground electrode in PG-C4D surrounded the sensing electrodes, while the ground electrode in traditional C4D lay in the middle of the sensing electrode pairs with width of $200 \mu \mathrm{m}$, as shown in Figure 1B,C. 


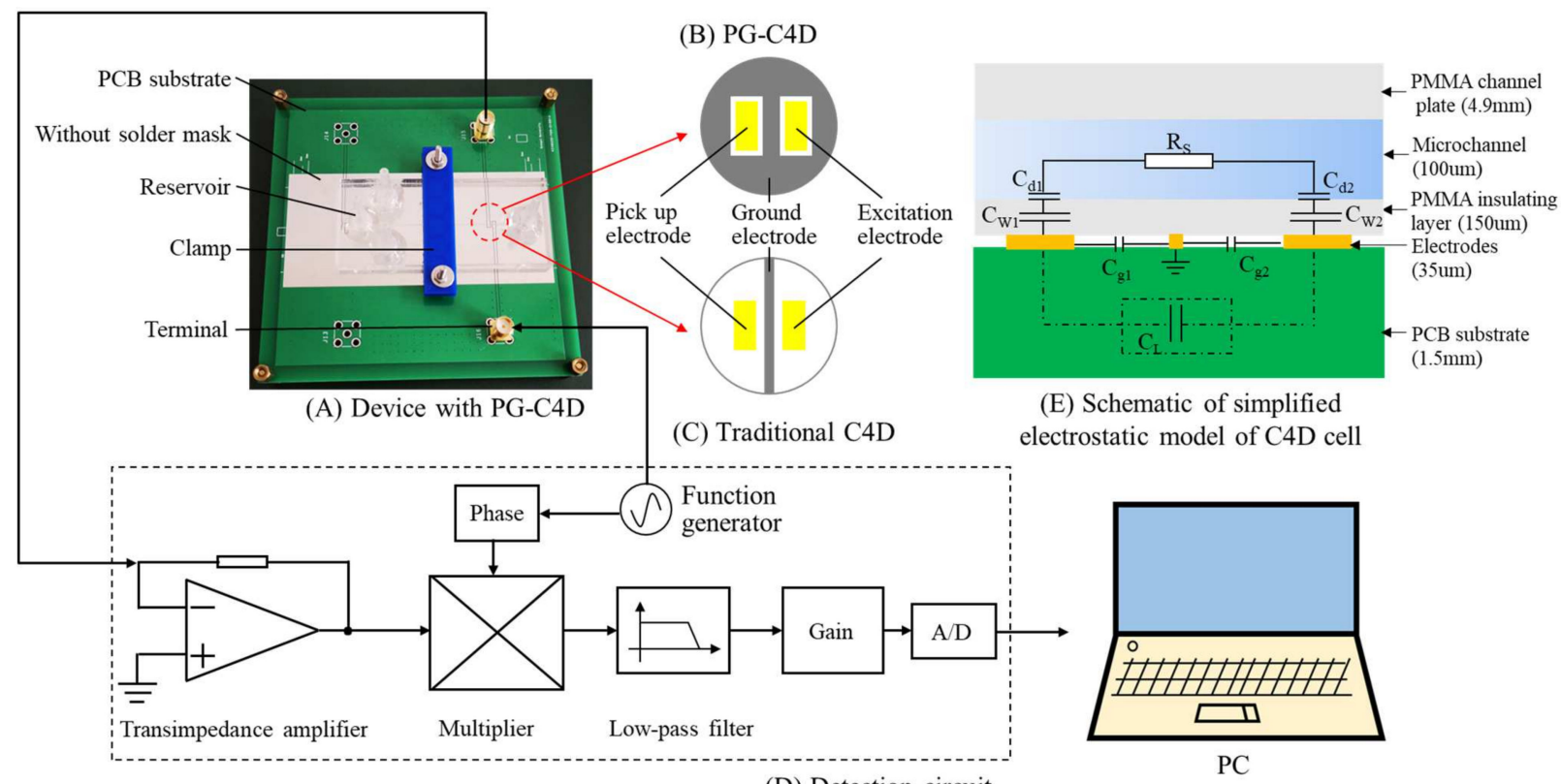

(D) Detection circuit

Figure 1. Schematic drawing of a microchip device with external C4D. (A) Device with PG-C4D (B) PG-C4D. (C) Traditional C4D. (D) Detection circuit. (E) Schematic of simplified electrostatic model of C4D cell.

The microchips consisted of a $5 \mathrm{~mm}$ thick PMMA plate and a $150 \mu \mathrm{m}$ thick PMMA film. PMMA plate was used as the microchannel layer. The PMMA film was used as the insulating layer. The microchip was fabricated using the following steps. First, the microchannels in the PMMA plate were fabricated by a CNC machine (X5 combo, SYIL MACHINE TOOLS Co., Ltd., Ningbo, China). The length of the injection and separation microchannels were $16 \mathrm{~mm}$ and $53 \mathrm{~mm}$, respectively. Both microchannels had a square cross section of $100 \mu \mathrm{m} \times 100 \mu \mathrm{m}$. Secondly, the PMMA plate with microchannels was cleaned with purified water in an ultrasonic cleaner (SB-5200DT, NINGBO SCIENTZ BIOTECHNOLOGY Co., Ltd., Ningbo, China) three times, 10 min each time. Then, the PMMA plate along with the PMMA film were air plasma treated at 700 mTorr at high power $(30 \mathrm{~W})$ for 5 min (PDC-002, Harrick Plasma, Ithaca, NY, USA). Next, the PMMA plate with microchannels was aligned onto the PMMA film and thermally pressed at $105^{\circ} \mathrm{C}$ under $0.3 \mathrm{MPa}$ for $15 \mathrm{~min}$, leading to a strong adhesion between the layers. Finally, the bases of plastic pipette tips were attached on the top of reservoirs on the PMMA plate, in order to connect the microchip with external devices. A device of microchip electrophoresis with PG-C4D based on PCB, CNC and thermal press packaging is easy to process and economical, which is favorable for commercialization.

\subsection{Reagents and Electrophoretic Procedures}

All reagents were of analytical grade and purchased from Macklin (Shanghai, China). The solutions were prepared using deionized water (resistivity $18.2 \mathrm{M} \Omega \cdot \mathrm{cm}$ ) processed through a purification system (Cascada I, PALL, Beijing, China). Stock solutions of cations $\left(\mathrm{K}^{+}, \mathrm{Na}^{+}\right.$, and $\left.\mathrm{Li}^{+}, 5 \mathrm{mM}\right)$ were prepared from their corresponding chloride salts. The $60 \mathrm{mM}$ stock solutions of L-histidine (His) and 2-(N-morpholino)-ethanesulfonic acid (MES) were prepared daily. A mixture of $20 \mathrm{mM}$ MES and $20 \mathrm{mM}$ His at $\mathrm{pH} 6.0$ was used as running buffer, and was filtered through 0.22 um nylon syringe filters before use.

To improve the repeatability, prior to use, the microchannels were washed with $100 \mathrm{mM}$ sodium hydroxide solution, deionized water, and running buffer for $15 \mathrm{~min}$, respectively. The sample solution was prepared daily in running buffer, avoiding sample stacking. At the end of a working day, the microchips were rinsed with deionized water, to 
prevent clogging and contamination. Sample injection was performed electrokinetically using cross-injection method.

When the sample passed through the detection cell, the cell impedance would change, thus the sinusoidal current output of the PG-C4D would change. The I/V conversion was completed by a transimpedance amplifier (OPA656, Texas Instruments, Austin, TX, USA) with a feedback resistor of $2 \mathrm{M} \Omega$ [30]. This voltage signal was then lock-in amplified [31], filtered and gained, and finally sampled by an acquisition unit as shown in Figure 2. The high-voltage modules and associated circuits used in the system have been described in the previous work [32]. The data acquisition was done by a data acquisition unit (MAX194, Maxim Integrated, San Jose, CA, USA) and a software written in LABVIEW (National Instruments, Austin, TX, USA). The software was also used to control the high voltage switching from injection to separation step.

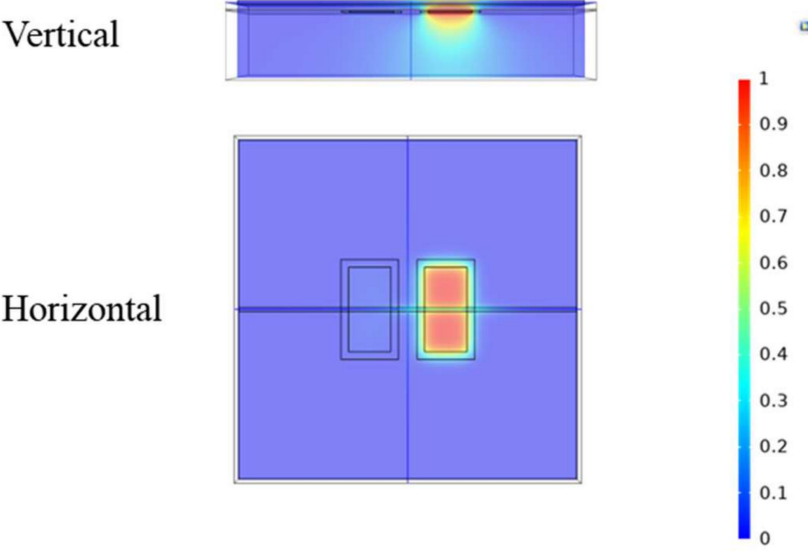

(A)

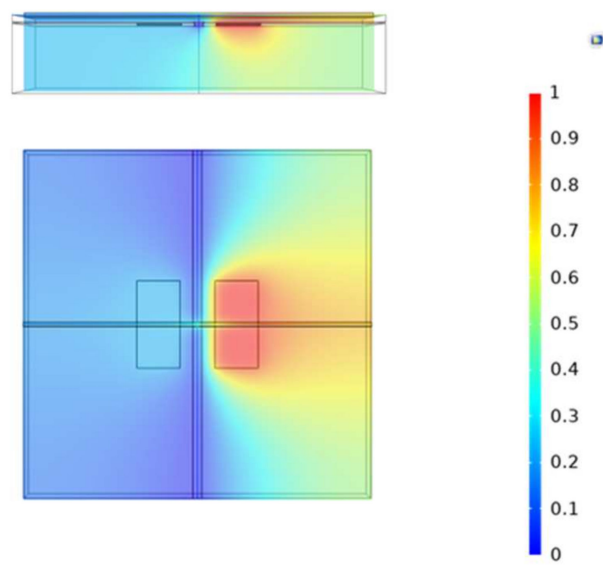

(B)

Figure 2. Simulated electric potential distribution of C4D cell, with both vertical and horizontal direction. A model (A) with PG-C4D feature and (B) with traditional C4D feature.

\subsection{Electrostatic Model and Simulation Settings of C4D}

In order to obtain the influence of stray capacitance on solution conductivity detection, the equivalent circuit model was analyzed using finite element simulation. C4D with different ground electrode design adopted the electrical model shown in Figure 1E, which was simplified from an RC network proposed by da Silva and do Lago et al. $[5,6]$. $C_{L}$ is the stray capacitance. $C_{W 1}$ and $C_{W 2}$ are the wall capacitance of sensing electrodes coupled to the microchip, which are equal to $\mathrm{C}_{\mathrm{W}}$. $\mathrm{C}_{\mathrm{g} 1}$ and $\mathrm{C}_{\mathrm{g} 2}$ are the coupling capacitance between the sensing electrode and the ground electrode, which has negligible effect on the output current of the $C 4 \mathrm{D}$ [10]. The electric double layer $\mathrm{C}_{\mathrm{d} 1}$ and $\mathrm{C}_{\mathrm{d} 2}$ are very important in contact conductivity detection, but can be ignored in contactless conductivity detection [5]. Then the impedance of the C4D cell is defined as Z [11]. As shown in Equation (1), it is a function of $\mathrm{C}_{\mathrm{W}}, \mathrm{R}_{\mathrm{S}}$, and $\mathrm{C}_{\mathrm{L}}$.

$$
\begin{aligned}
& Z=\frac{1}{j \omega C_{L}} / /\left(R_{S}+\frac{2}{j \omega C_{W}}\right), \\
& \frac{1}{Z}=2 \mathrm{j} \pi \mathrm{fC} C_{L}+\frac{1}{\frac{1}{j \pi f C_{W}}+R_{S}},
\end{aligned}
$$

From Equation (1), $R_{S}$ is connected in series with $C_{W 1}$ and $C_{W 2}$, and then connected in parallel with $C_{L}$ to form a cell impedance. The reciprocal of the impedance, as shown in Equation (2), shows more clearly how the $C_{L}, C_{W}$, and $R_{S}$ affect the cell impedance. $\mathrm{C}_{\mathrm{L}}$ will cause additional and unwanted signals, which are not affected by the change in conductivity of solution. The unwanted effect of $C_{L}$ increases with frequency, and severely impairs the detection performance of the system. 
To study the stray capacitance generated by C4D with different ground electrode designs, a cell model was established by the Multiphysics simulation software COMSOL 5.6. The microchannel section area and electrode dimensions were set as mentioned above. To improve calculation efficiency, only the space near the sensing electrode is simulated. The three-dimensional model of the prototyped PG-C4D is shown in Appendix A, Figure A1. System default material parameters were adopted. Detailed information of the C4D is listed in Table 1.

Table 1. Detailed information of the simulated C4D structure.

\begin{tabular}{cccc}
\hline Title 1 & Materials & $\begin{array}{c}\text { Relative } \\
\text { Permittivity }\end{array}$ & Size \\
\hline Microchannel & Water & 81 & $\begin{array}{c}100 \mu \mathrm{m} \times 100 \mu \mathrm{m} \\
\text { (cross-section) }\end{array}$ \\
\hline $\begin{array}{c}\text { PMMA insulating } \\
\text { layer }\end{array}$ & PMMA & 2.9 & $150 \mu \mathrm{m}$ (thickness) \\
\hline $\begin{array}{c}\text { Sensing electrodes } \\
\text { PCB substrate }\end{array}$ & Cu & 1 & $\begin{array}{c}2 \mathrm{~mm} \times 1 \mathrm{~mm} \times 35 \mu \mathrm{m} \\
(\text { length } \times \text { width } \times \text { height })\end{array}$ \\
\hline
\end{tabular}

\section{Results and Discussion}

\subsection{Effect of Stray Capacitance on Cell Response}

The effect of stray capacitance in both PG-C4D and traditional C4D was simulated and calculated, demonstrating that planar grounded electrode would greatly decrease the stray capacitance. The simulation result was then validated by baseline strength testing.

The cell equivalent circuit and physical simulation model of $C 4 \mathrm{D}$ were established as mentioned in Section 2.3. The electric field distributions of both PG-C4D and traditional C4Ds were obtained. Figure 2A,B show the calculated electric field intensity distributions in vertical and horizontal direction for both C4Ds. For the PG-C4D, the electric field was concentrated around the electrode to which the positive potential was applied. This is due to the presence of the planar grounded electrode. While in traditional C4D, potential distributed away from the electrode of which the positive potential was applied. Furthermore, the potential of the other electrode without positive potential was not $0 \mathrm{~V}$. The potential distribution of the traditional C4D meant that there was charge accumulation on the other sensing electrode (the terminal where no potential was applied). This indicates that there is stray capacitance between the sensing electrodes in traditional C4D. The electric field distribution indicated that traditional C4D had larger stray capacitance than PG-C4D.

The stray capacitance was calculated based on the simulation result. Detailed calculation steps are shown in Appendix B [33]. The stray capacitance of the PG-C4D was calculated to be $11.698 \mathrm{fF}$, while the stray capacitance of traditional C4D was calculated to be 38.81fF, which was more than three times of that of the PG-C4D.

To confirm the simulation result that the stray capacitance of PG-C4D was greatly reduced, the output signal (the average of baseline intensity) of the transimpedance amplifier was tested. It can be seen from Figure 3A that, compared to traditional C4D, PG-C4D effectively reduced the baseline intensity to one order lower than that of traditional C4D. The measurement of peak to peak (output) can avoid interference from other parts of the circuit, which is an indicator of whether the stray capacitance had reduced or not, as shown in Figure 3B. The baseline intensity result was on par with the previous reported C4D with the ground plane perpendicular to the channel [16]. The layout of the PG-C4D was simpler, more convenient, and suitable for large-scale production, and showed a good suppression effect on stray capacitance. In addition, the output signal of the transimpedance amplifier became distorted once the excitation amplitude exceeded $10 \mathrm{~V}$. As shown in diagram $\mathrm{C}$ of Figure 3B, this distorted phenomenon indicated that the signal cannot keep sinusoidal signal, due to the bandwidth and output voltage limitation of the transimpedance amplifier 
$(\mathrm{OPA} 656, \pm 5 \mathrm{~V})$. This phenomenon also proved that the large stray capacitance in traditional C4D limited the applicable range of the excitation signal. The noise would also be more obvious under stronger excitation voltage. An effective method to introduce differential design would reduce the noise caused by high excitation voltage, but it would increase the cost of the system $[20,26,28]$. It could be concluded that PG-C4D can greatly reduce the interference current of the pick-up electrode due to the reduction of stray capacitance, and thus have better signal-to-noise ratio and detection sensitivity.

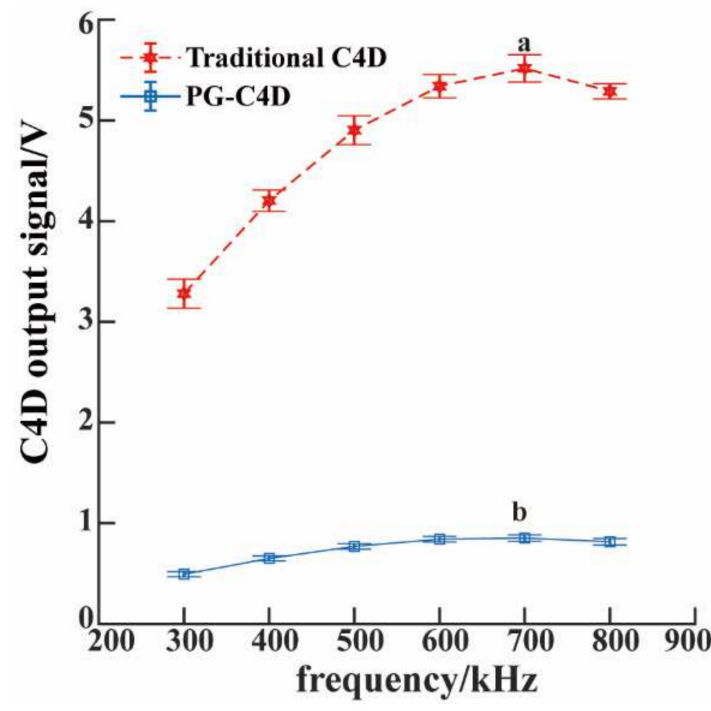

(A)

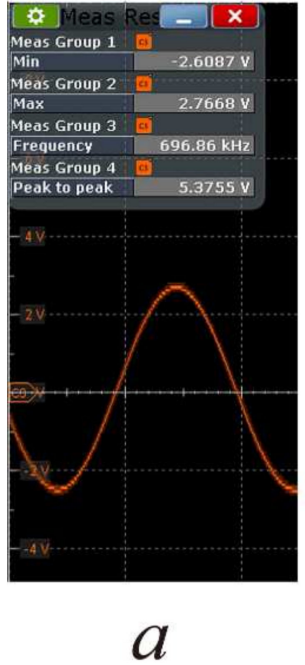

$a$

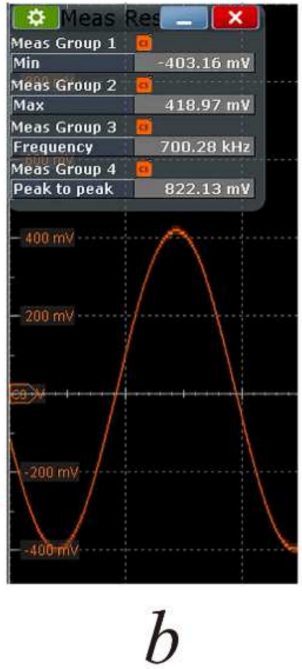

(B)

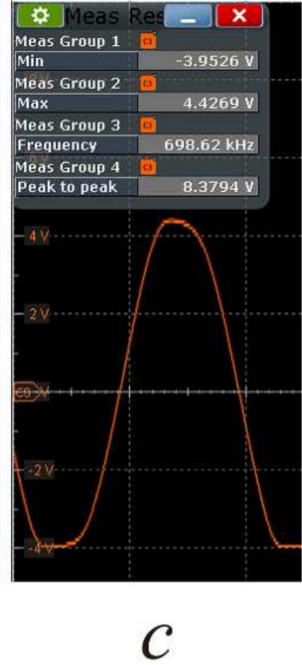

C

Figure 3. (A) C4D output signal. Red dashed line stands for the traditional C4D, and the blue continuous line stands for the PG-C4D. The error bars are the standard deviation of the measurements $(n=3)$. (B) Maximum output strength of the transimpedance amplifier. a: traditional C4D. b: PG-C4D. c: the excitation amplitude exceeded $10 \mathrm{~V}$ in traditional C4D (distorted). Experimental conditions: channel filled with running buffer, oscilloscope filter cutoff frequency, $5 \mathrm{MHz}$.

\subsection{Performance Comparison}

The analytical performance of C4Ds with different ground electrodes was evaluated by inorganic cations detection experiment. The inorganic cations of potassium $\left(\mathrm{K}^{+}\right)$, sodium $\left(\mathrm{Na}^{+}\right)$, and lithium $\left(\mathrm{Li}^{+}\right)$in the mixed solution of each ionic compounds were used as detection objects. The raw electropherograms of the three inorganic cations are shown in Figure 4 . The RSD values of migration times, peak areas, and peak heights were calculated to compare the detection results of the two ground electrode configurations. Table 2 shows the calculated results for the $0.5 \mathrm{mM}$ concentration level for five consecutive injections $(n=5)$.

The high-voltage switching at the moment of sampling would cause the output of electronic devices to jump, as shown by the arrows marked in Figure 4A,B. The inset diagrams in Figure 4 showed the raw baseline signal noise, without any filtering algorithm, to better estimate the ability of PG-C4D to suppress noise. It could be seen from the inset diagram in Figure $4 \mathrm{~A}$ that the noise amplitude of the separated sample and running buffer measured by PG-C4D was approximately $4 \mathrm{mV}$. The peak heights for $\mathrm{K}^{+}, \mathrm{Na}^{+}$, and $\mathrm{Li}^{+}$ were approximately $41.2 \mathrm{mV}, 35.3 \mathrm{mV}$, and $23.7 \mathrm{mV}$, respectively. Here, the peak height was used to represent the peak intensity. The calculation process of the peak height was as follows. First, the signal was filtered, then peak function in MATLAB was applied to find the starting point, vertex, and end point of the peak. Finally, the peak height was obtained by subtracting the mean of the start and end points from the peak apex value. Signal-to-noise ratio of the peak height is greater than 3 for all the three ions. Though the concentrations of $\mathrm{K}^{+}, \mathrm{Na}^{+}$, and $\mathrm{Li}^{+}$were all the same in the sample, peak intensities 
decrease in the order of $\mathrm{K}^{+}, \mathrm{Na}^{+}$, and $\mathrm{Li}^{+}$, which was related to the ionic conductivities of these ions [34]. The noise level in the traditional C4D is approximately $25 \mathrm{mV}$, as shown in the inset diagram in Figure $4 \mathrm{~B}$. The peak height for $\mathrm{K}^{+}, \mathrm{Na}^{+}$, and $\mathrm{Li}^{+}$were about $94.5 \mathrm{mV}$, $75.7 \mathrm{mV}$, and $54.7 \mathrm{mV}$, respectively. The noise in the signal seriously affects the performance of the device with traditional C4D.

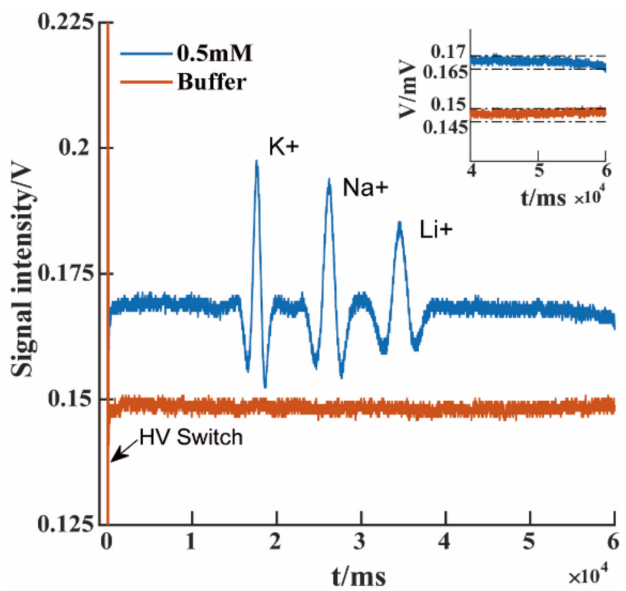

(A)

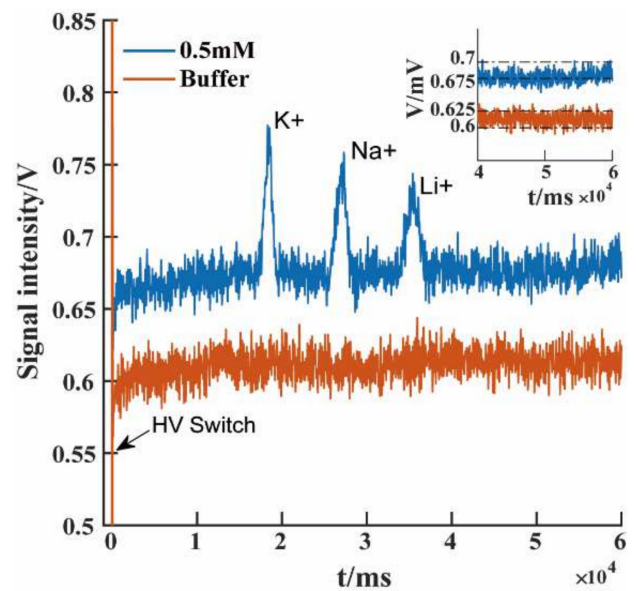

(B)

Figure 4. Raw electropherograms showing the separation of inorganic cations $\left(\mathrm{K}^{+}, \mathrm{Na}^{+}\right.$, and $\mathrm{Li}^{+}$, $0.5 \mathrm{mM}$ each). (A) PG-C4D and (B) traditional C4D. Injection voltage: $500 \mathrm{~V}$; separation voltage: 1000 V. Running buffer: 20 mM MES/His, pH 6.0. Detection conditions: 700-kHz, 5Vpp.

Table 2. Response Characteristics of PG-C4D and Traditional C4D $\left(\mathrm{K}^{+}, \mathrm{Na}^{+}\right.$, and $\mathrm{Li}^{+}, 0.5 \mathrm{mM}$ each).

\begin{tabular}{cccc}
\hline Ion ${ }^{1}$ & Indicator & PG-C4D (RSD) & $\begin{array}{c}\text { Traditional C4D } \\
\text { (RSD) }\end{array}$ \\
\hline \multirow{2}{*}{$\mathrm{K}^{+}$} & Migration Time $(\mathrm{ms})$ & $0.15 \%$ & $0.24 \%$ \\
\cline { 2 - 4 } & Area $(\mathrm{mV} \times \mathrm{ms})$ & $1.56 \%$ & $2.48 \%$ \\
& Height $(\mathrm{mV})$ & $0.43 \%$ & $4.74 \%$ \\
\hline \multirow{2}{*}{$\mathrm{Na}^{+}$} & Migration Time $(\mathrm{ms})$ & $0.18 \%$ & $0.39 \%$ \\
& Area $(\mathrm{mV} \times \mathrm{ms})$ & $1.57 \%$ & $4.40 \%$ \\
& Height $(\mathrm{mV})$ & $1.94 \%$ & $2.84 \%$ \\
\hline \multirow{2}{*}{$\mathrm{Li}^{+}$} & Migration Time $(\mathrm{ms})$ & $0.23 \%$ & $0.63 \%$ \\
& Area $(\mathrm{mV} \times \mathrm{ms})$ & $2.88 \%$ & $9.46 \%$ \\
& Height $(\mathrm{mV})$ & $3.42 \%$ & $6.28 \%$ \\
\hline
\end{tabular}

${ }^{1}$ Data were filtered by Butterworth (cutoff frequency $=5 \mathrm{~Hz}$ ) and obtained by trapezoidal numerical integration algorithm.

Compared with traditional C4D, the absolute peak height value of PG-C4D was reduced due to a slight loss of signal current. However, the signal-to-noise ratio was improved by $270 \%, 290 \%$, and $270 \%$ for $\mathrm{K}^{+}, \mathrm{Na}^{+}$, and $\mathrm{Li}^{+}$, respectively. For traditional C4D, a large part of the current measured by the electronics was actually introduced by stray capacitance. The stray capacitance current caused larger output signal of the C4D, but it actually enhanced the noise proportion, which was harmful to the sensitivity of the system.

It could be seen from Table 2 that the RSD of migration time of $\mathrm{K}^{+}, \mathrm{Na}^{+}$, and $\mathrm{Li}^{+}$ increased slightly for both PG-C4D and traditional C4D, which was due to discrimination caused by electric injection $[35,36]$. The results in Table 2 demonstrated that the PG-C4D had better repeatability for quantitative analysis. For PG-C4D, the RSD for peak area was found to be $1.56 \%$ for $\mathrm{K}^{+}, 1.57 \%$ for $\mathrm{Na}^{+}$, and $2.88 \%$ for $\mathrm{Li}^{+}$, and the RSD for peak height was found to be $0.43 \%$ for $\mathrm{K}^{+}, 1.92 \%$ for $\mathrm{Na}^{+}$, and $3.42 \%$ for $\mathrm{Li}^{+}$. The results were on par with those obtained on referenced C4D with capillary electrophoresis [28] or complex top-bottom cell with precise shield of microchip electrophoresis [21]. 


\subsection{Separation and Quantification of Cations}

To demonstrate the quantitative performance of PG-C4D on cationic mixtures, five samples with different concentrations were tested. Figure 5A shows the raw electropherograms of the five concentration levels, under the optimal excitation signal conditions. The detection limits of $\mathrm{K}^{+}, \mathrm{Na}^{+}$, and $\mathrm{Li}^{+}$cations were $0.05 \mathrm{mM}, 0.1 \mathrm{mM}$, and $0.1 \mathrm{mM}$, respectively. The limit of detection was defined as the concentration at which the ratio of the peak height to the baseline noise obtained by filtering $(S / N \geq 3)$, as shown in Appendix $C$, Figure A2. The detection sensitivity here is relatively poor, compared with the $\mathrm{C} 4 \mathrm{D}$ for microchip electrophoresis in a previous report [16]. However, under the same conditions, the detection limit of the proposed PG-C4D is much better than that of the traditional C4D. The detection limit of traditional C4D is around $0.25 \mathrm{mM}$, as shown in Appendix D, Figure A3. However, traditional C4D baseline noise fluctuates randomly and cannot be maintained at a stable level. The detection sensitivity of the proposed PG-C4D could be further improved by high voltage excitation signal $[21,28]$ and a dedicated low-noise amplifier, but these devices would increase the cost of the total system [25,26].

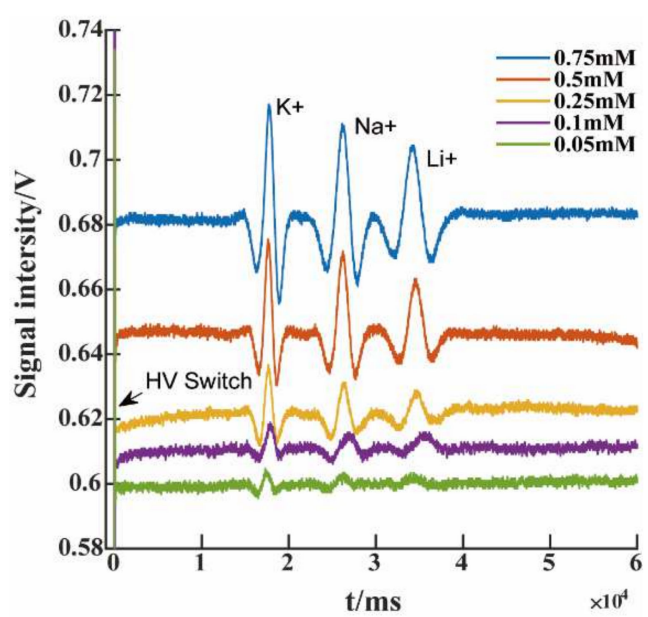

(A)

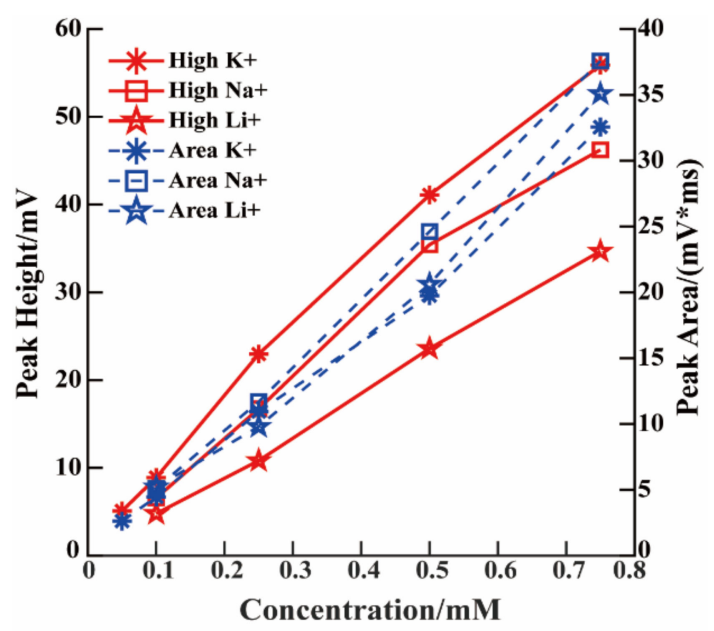

(B)

Figure 5. (A) An electropherogram of five concentrations. (B) Calibration curves of peak height sensitivity and peak area sensitivity of microchip electrophoresis with PG-C4D. Operational conditions were the same as in Figure 4.

The relation between the peak height/peak area and the concentration was investigated. The results showed that the peak height has higher concentration resolution. As shown in Figure 5B, the peak height/concentration correlation coefficients of $\mathrm{K}^{+}, \mathrm{Na}^{+}$, and $\mathrm{Li}^{+}$were $\mathrm{R}^{2}=0.9931, \mathrm{R}^{2}=0.9864$, and $\mathrm{R}^{2}=0.9986$, respectively, and the corresponding sensitivities were $73.331\left(\mathrm{~K}^{+}\right), 62.213\left(\mathrm{Na}^{+}\right)$, and $46.658\left(\mathrm{Li}^{+}\right) \mathrm{mV} / \mathrm{mM}$, respectively. The correlation coefficients of the peak area/concentration of $\mathrm{K}^{+}, \mathrm{Na}^{+}$, and $\mathrm{Li}^{+}$were $R^{2}=0.995, R^{2}=0.9991$, and $R^{2}=0.9865$, respectively, and the corresponding sensitivities were $41.694\left(\mathrm{~K}^{+}\right), 50.285\left(\mathrm{Na}^{+}\right)$, and $46.145\left(\mathrm{Li}^{+}\right) \mathrm{mV} \times \mathrm{ms} / \mathrm{mM}$, respectively. These results are much better than those of the $\mathrm{C} 4 \mathrm{D}$ with differential mode designed by Xiao [27] in capillary electrophoresis (such as, $\left.2.2 \times 10^{-3}\left(\mathrm{~K}^{+}\right), 2.3 \times 10^{-3}\left(\mathrm{Li}^{+}\right) \mathrm{mV} / \mu \mathrm{M}\right)$. The linear coefficients between the peak height against ion concentration and peak area against ion concentration of the same ion were almost the same. However, the sensitivity for peak height/concentration was higher than that of peak area/concentration. That is, peak height was a better indicator for concentration detection.

\section{Conclusions}

The reported PG-C4D had much lower stray capacitance than traditional C4D, thus the baseline intensity and noise amplitude of the detection cell were smaller, resulting in higher signal-to-noise ratio, detection sensitivity, and repeatability. Electrical field simulation and 
baseline strength test showed that the stray capacitance of PG-C4D was less than 1/3 of that of traditional C4D. The background baseline intensity of the PG-C4D was less than $1 / 6$ of that of traditional C4D, and the noise amplitude of baseline was reduced from $25 \mathrm{mV}$ to $4 \mathrm{mV}$. Electrophoretic detection experiments of inorganic cations showed that the RSD of migration time, peak area, and peak height were less than $0.3 \%, 3 \%$, and $4 \%$, respectively. The detection limits of inorganic $\mathrm{K}^{+}, \mathrm{Na}^{+}$, and $\mathrm{Li}^{+}$are $0.05,0.1$, and $0.1 \mathrm{mM}$, respectively. Experimental results showed that the designed PG-C4D can be used in a wide range of excitation frequencies and amplitudes, which was especially favorable for systems with large signal excitation.

This paper proposes a new C4D device for microchip electrophoresis with low stray capacitance, high sensitivity, and high repeatability, which requires no special shielding and chip size and shape requirement. At the same time, the microchip and electrodes are produced independently, and the microchip is easily replaced through mechanical assembly. PCB, CNC machining, and hot-press packaging greatly reduce development costs, which are of great significance in device integration and large-scale applications. The designed PG-C4D shows great potential for microchip electrophoresis, including the detection of industrial wastewater, agricultural irrigation water nutrients, and environmental conditions.

Author Contributions: Writing-original draft preparation, J.W.; planning and performing the experiments, J.W. and Y.L.; software support, W.H. and J.W.; theory consultation and formal analysis, W.H.; writing-review and editing, Y.C.; supervision, Y.C.; project administration, H.Y.; funding acquisition, H.Y. All authors have read and agreed to the published version of the manuscript.

Funding: This research was funded by Key-Area Research and Development Program of Guangdong Province (2019B020219003) and Guangxi Bagui Scholars Project (No.C3010099204).

Informed Consent Statement: Not applicable.

Data Availability Statement: Data is contained within the article.

Acknowledgments: Thanks to the teachers from the School of Mechanical Engineering of Guangxi University for their support in the research, as well as their opinions and suggestions on system construction and writing.

Conflicts of Interest: The authors declare no conflict of interest.

\section{Appendix A}

A model of the designed device geometry is shown in Figure A1. This device contains a 4-layer structure, the layers of which are microchannels, PMMA insulating layer, electrodes, and the PCB substrate, respectively.

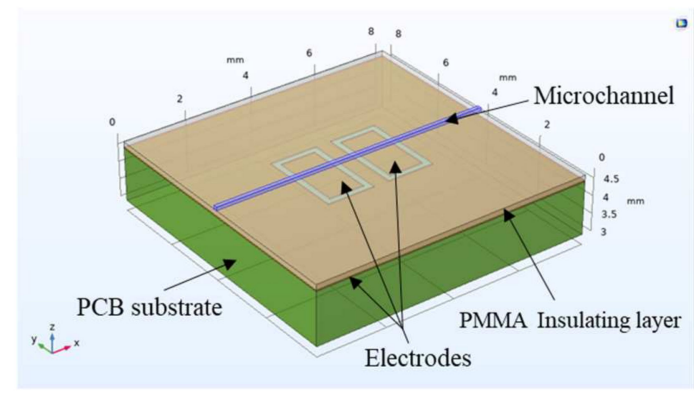

Figure A1. Three-dimensional model of the prototyped PG-C4D.

\section{Appendix B}

To calculate the capacitance, it was assumed that the sensing electrodes and the ground electrode form a mutual capacitance matrix. The capacitor matrix was composed of three capacitors, $\mathrm{C}_{\mathrm{g} 1}, \mathrm{C}_{\mathrm{g} 2}$, and $\mathrm{C}_{\mathrm{L}}$, as shown in Figure 3. The calculation principle was slightly more complicated: here is a brief overview. Potentials were applied to the two 
sensing electrodes, respectively, and the corresponding charges on the electrodes were measured. The next step was to get the mutual capacitance matrix by converting the Maxwell capacitance matrix. COMSOL used stationary source sweep/or manual terminal sweep to set one terminal to $1 \mathrm{~V}$ and all other terminals to ground.

In the drop-down list of calculation results, capacitance matrix with different symbols could be obtained through global matrix calculation. In this way, we could obtain the mutual capacitance matrix between the three electrodes, and then obtained the stray capacitance coupled between the sensing electrodes.

\section{Appendix C}

Figure A2 showed the filtered peaks and the fluctuation of baseline noise within $10 \mathrm{~s}$. The filtered baseline noise was lower than $1.5 \mathrm{mV}$. It could be concluded that the filtering process can further improve the signal-to-noise ratio and it is beneficial for improving the detection limit of the system.

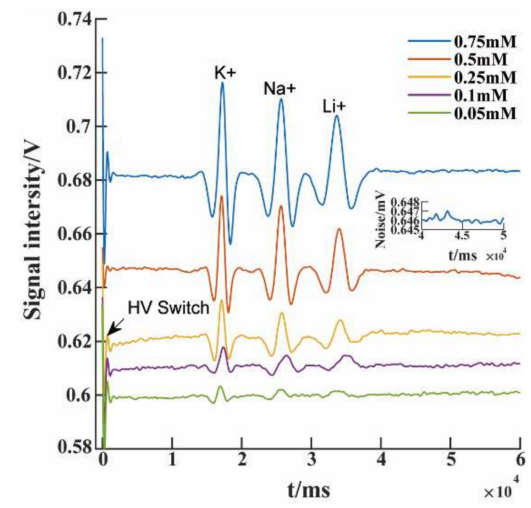

Figure A2. Signals filtered by Butterworth (cutoff frequency $=5 \mathrm{~Hz}$ ), the inset diagram is the baseline noise fluctuation.

\section{Appendix D}

Three samples of different concentrations were tested on the traditional C4D to compare the performance of the proposed PG-C4D with the traditional C4D, as shown in Figure A3. When the sample concentration is $0.5 \mathrm{mM}$, the peak heights for $\mathrm{K}^{+}, \mathrm{Na}^{+}$, and $\mathrm{Li}^{+}$are about $94.5 \mathrm{mV}, 75.7 \mathrm{mV}$, and $54.7 \mathrm{mV}$, respectively. When the sample concentration is $0.25 \mathrm{mM}$, the peak height for $\mathrm{K}^{+}$is $52.6 \mathrm{mV}$, and $\mathrm{Na}^{+} 23.5 \mathrm{mV}$, while the peak height of $\mathrm{Li}^{+}$cannot be identified due to excessive signal noise. When the sample concentration is $0.1 \mathrm{mM}$, none of the three ionic ions can be identified. These results also showed that the fluctuation amplitude of the baseline noise is unstable, which indicates that the traditional C4D had strong instability.

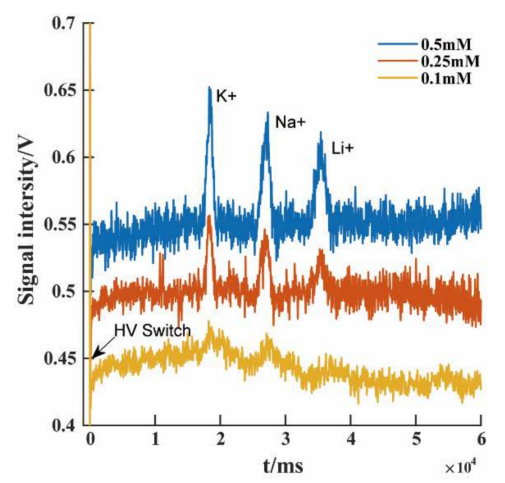

Figure A3. An electropherogram of three concentrations of device with traditional C4D. Operational conditions were the same as in Figure 5. 


\section{References}

1. Hauser, P.C.; Kuban, P. Capacitively coupled contactless conductivity detection for analytical techniques-Developments from 2018 to 2020. J. Chromatogr. A 2020, 1632, 461616. [CrossRef]

2. Zhang, M.; Phung, S.C.; Smejkal, P.; Guijt, R.M.; Breadmore, M.C. Recent trends in capillary and micro-chip electrophoretic instrumentation for field-analysis. Trends Environ. Anal. Chem. 2018, 18, 1-10. [CrossRef]

3. Ou, X.; Chen, P.; Huang, X.; Li, S.; Liu, B.-F. Microfluidic chip electrophoresis for biochemical analysis. J. Sep. Sci. 2020, 43, 258-270. [CrossRef]

4. Le, T.B.; Hauser, P.C.; Pham, T.N.M.; Kieu, T.L.P.; Le, T.P.Q.; Hoang, Q.A.; Le, D.C.; Nguyen, T.A.H.; Mai, T.D. Low-cost and versatile analytical tool with purpose-made capillary electrophoresis coupled to contactless conductivity detection: Application to antibiotics quality control in Vietnam. Electrophoresis 2020, 41, 1980-1990. [CrossRef] [PubMed]

5. Zemann, A.J.; Mayrhofer, K.; Schnell, E.; Bonn, G.K. Contactless conductivity detection for capillary electrophoresis. Abstr. Pap. Am. Chem. Soc. 1998, 216, U162. [CrossRef]

6. Da Silva, J.A.F.; do Lago, C.L. An oscillometric detector for capillary electrophoresis. Anal. Chem. 1998, 70, 4339-4343. [CrossRef]

7. Pumera, M.; Wang, J.; Opekar, F.; Jelinek, I.; Feldman, J.; Lowe, H.; Hardt, S. Contactless conductivity detector for microchip capillary electrophoresis. Anal. Chem. 2002, 74, 1968-1971. [CrossRef] [PubMed]

8. Gamat, S.N.; Fotouhi, L.; Talebpour, Z. The application of electrochemical detection in capillary electrophoresis. J. Iran. Chem. Soc. 2017, 14, 717-725. [CrossRef]

9. Brito-Neto, J.G.A.; da Silva, J.A.F.; Blanes, L.; do Lago, C.L. Understanding capacitively coupled contactless conductivity detection in capillary and microchip electrophoresis. Part 1. Fundamentals. Electroanalysis 2005, 17, 1198-1206. [CrossRef]

10. Brito-Neto, J.G.A.; da Silva, J.A.F.; Blanes, L.; do Lago, C.L. Understanding capacitively coupled contactless conductivity detection in capillary and microchip electrophoresis. Part 2. Peak shape, stray capacitance, noise, and actual electronics. Electroanalysis 2005, 17, 1207-1214. [CrossRef]

11. Kuban, P.; Hauser, P.C. Ten years of axial capacitively coupled contactless conductivity detection for CZE-A review. Electrophoresis 2009, 30, 176-188. [CrossRef] [PubMed]

12. Kuban, P.; Hauser, P.C. Fundamental aspects of contactless conductivity detection for capillary electrophoresis. Part I: Frequency behavior and cell geometry. Electrophoresis 2004, 25, 3387-3397. [CrossRef] [PubMed]

13. Koczka, P.I.; Bodoki, E.; Gaspar, A. Application of capacitively coupled contactless conductivity as an external detector for zone electrophoresis in poly(dimethylsiloxane) chips. Electrophoresis 2016, 37, 398-405. [CrossRef] [PubMed]

14. Takekawa, V.S.; Marques, L.A.; Strubinger, E.; Segato, T.P.; Bogusz, S., Jr.; Brazaca, L.C.; Carrilho, E. Development of low-cost planar electrodes and microfluidic channels for applications in capacitively coupled contactless conductivity detection ((CD)-D-4). Electrophoresis 2021, 42, 1560-1569. [CrossRef] [PubMed]

15. Liu, J.; Xu, F.; Wang, S.; Chen, Z.; Pan, J.; Ma, X.; Jia, X.; Xu, Z.; Liu, C.; Wang, L. A polydimethylsiloxane electrophoresis microchip with a thickness controllable insulating layer for capacitatively coupled contactless conductivity detection. Electrochem. Commun. 2012, 25, 147-150. [CrossRef]

16. Kuban, P.; Hauser, P.C. Evaluation of microchip capillary electrophoresis with external contactless conductivity detection for the determination of major inorganic ions and lithium in serum and urine samples. Lab Chip 2008, 8, 1829-1836. [CrossRef]

17. Guijt, R.M.; Evenhuis, C.J.; Macka, M.; Haddad, P.R. Conductivity detection for conventional and miniaturised capillary electrophoresis systems. Electrophoresis 2004, 25, 4032-4057. [CrossRef]

18. Wang, Y.; Cao, X.; Hogan, A.; Messina, W.; Moore, E.J. Fabrication of a grounded electrodes cell with Capacitively Coupled Contactless Conductivity Detection technique in a microchip capillary electrophoresis application. In Proceedings of the 18th IEEE International Conference on Nanotechnology (IEEE-NANO), Tyndall Natl Inst, Cork, Ireland, 23-26 July 2018.

19. Petkovic, K. An integrated portable multiplex microchip device for fingerprinting chemical warfare agents. Micromachines Micromachines 2019, 10, 617. [CrossRef]

20. Guijt, R.M.; Armstrong, J.P.; Candish, E.; Lefleur, V.; Percey, W.J.; Shabala, S.; Hauser, P.C.; Breadmore, M.C. Microfluidic chips for capillary electrophoresis wionth integrated electrodes for capacitively coupled conductivity detection based on printed circuit board technology. Sens. Actuators B Chem. 2011, 159, 307-313. [CrossRef]

21. Mahabadi, K.A.; Rodriguez, I.; Lim, C.Y.; Maurya, D.K.; Hauser, P.C.; de Rooij, N.F. Capacitively coupled contactless conductivity detection with dual top-bottom cell configuration for microchip electrophoresis. Electrophoresis 2010, 31, 1063-1070. [CrossRef]

22. Kang, Q.; Shen, D.; Li, Q.; Hu, Q.; Dong, J.; Du, J.; Tang, S. Reduction of the impedance of a contactless conductivity detector for microchip capillary electrophoresis: Compensation of the electrode impedance by addition of a series inductance from a piezoelectric quartz crystal. Anal. Chem. 2008, 80, 7826-7832. [CrossRef]

23. Zhang, Z.; Li, D.; Liu, X.; Subhani, Q.; Zhu, Y.; Kang, Q.; Shen, D. Determination of anions using monolithic capillary column ion chromatography with end-to-end differential contactless conductometric detectors under resonance approach. Analyst 2012, 137, 2876-2883. [CrossRef]

24. Huang, J.; Ji, H.; Huang, Z.; Wang, B.; Li, H. A New Contactless Method for Velocity Measurement of Bubbleand Slug in Millimeter-Scale Pipelines. IEEE Access 2017, 5, 12168-12175. [CrossRef]

25. Laugere, F.; Guijt, R.M.; Bastemeijer, J.; van der Steen, G.; Berthold, A.; Baltussen, E.; Bossche, A. On-chip contactless four-electrode conductivity detection for capillary electrophoresis devices. Anal. Chem. 2003, 75, 306-312. [CrossRef] [PubMed] 
26. Fercher, G.; Haller, A.; Smetana, W.; Vellekoopt, M.J. End-to-End Differential Contact less Conductivity Sensor for Microchip Capillary Electrophoresis. Anal. Chem. 2010, 82, 3270-3275. [CrossRef]

27. Wang, C.; Xing, H.; Zheng, B.; Yuan, H.; Xiao, D. Simulation and Experimental Study on Doubled-Input Capacitively Coupled Contactless Conductivity Detection of Capillary Electrophoresis. Sci. Rep. 2020, 10, 7944. [CrossRef] [PubMed]

28. Stojkovic, M.; Schlensky, B.; Hauser, P.C. Referenced Capacitively Coupled Conductivity Detector for Capillary Electrophoresis. Electroanalysis 2013, 25, 2645-2650. [CrossRef]

29. Chang, Y.; You, H. A hybrid adhesive bonding of PMMA and PCB with an application on microchip electrophoresis. Anal. Methods 2019, 11, 1229-1236. [CrossRef]

30. Liu, B.; Jin, Q.; Zhang, Y.; Mayer, D.; Krause, H.-J.; Zhao, J.; Offenhaeusser, A. A simple poly(dimethylsiloxane) electrophoresis microchip with an integrated contactless conductivity detector. Microchim. Acta 2011, 172, 193-198. [CrossRef]

31. Liu, B.; Zhang, Y.; Mayer, D.; Krause, H.-J.; Jin, Q.; Zhao, J.; Offenhäusser, A.; Xu, Y. Determination of heavy metal ions by microchip capillary electrophoresis coupled with contactless conductivity detection. Electrophoresis 2012, 33, 1247-1250. [CrossRef] [PubMed]

32. Huang, Z.; Yang, M.; You, H.; Xie, Y. Simultaneous Determination of Inorganic Cations and Anions in Microchip Electrophoresis Using High-voltage Relays. Anal. Sci. 2018, 34, 801-805. [CrossRef] [PubMed]

33. How to Calculate the Capacitance Matrix in COMSOL Multiphysics®. Available online: http://cn.comsol.com/blogs/how-tocalculate-a-capacitance-matrix-in-comsol-multiphysics (accessed on 17 June 2017).

34. Lichtenberg, J.; de Rooij, N.F.; Aeroporto, E. A microchip electrophoresis system with integrated in-plane electrodes for contactless conductivity detection. Electrophoresis 2002, 23, 3769-3780. [CrossRef]

35. Gaudry, A.J.; Nai, Y.H.; Guij, R.M.; Breadmore, M.C. Polymeric Microchip for the Simultaneous Determination of Anions and Cations by Hydrodynamic Injection Using a Dual-Channel Sequential Injection Microchip Electrophoresis System. Anal. Chem. 2014, 86, 3380-3388. [CrossRef] [PubMed]

36. Ha, N.S.; Ly, J.; Jones, J.; Cheung, S.; van Dam, R.M. Novel volumetric method for highly repeatable injection in microchip electrophoresis. Anal. Chim. Acta 2017, 985, 129-140. [CrossRef] [PubMed] 